DOI: $10.17805 /$ ggz.2018.5.9

\title{
Регулирование технологий виртуальной реальности: к первому российскому кодексу этического поведения
}

\author{
М. А. Пронин
}

Институт философии РАН,

О. Н. Раев

Всероссийский государственный институт кинематографии им. С. А. Герасимова

В статье представлена современная ситуация с этическим регулированием технологий виртуальной, дополненной и замещающей реальностей (TVR) в России. В рамках «философии как экспертизы» (термин Б. Г. Юдина) изложены аргументы, характеризующие гуманитарное измерение TVR как технологии редактирования сознания. В этой связи указано на необходимость взять данные технологии под общественный, этический и юридический контроль.

Переведен на русский язык, с необходимыми комментариями, и вводится в научный оборот первый зарубежный «VERE-кодекс этического поведения. Рекомендачии для добросовестных научных исследований (good scientific practice) и потребителей VR-технологий», опубликованный M. Maдари и Т. Метиингером в 2016 г. Обсуждены проблемы проактивного поведения ученых и готовности / неготовности средств массовой информаџии писать не только о возможностях, но и угрозах и рисках TVR, которые в полной мере еще не известны и до кониа не осознаются.

Описаны первые шаги российского профессионального сообщества, занятого разработками, внедрением и использованием TVR, в направлении их регулирования - к разработке и обсуждению «Деклараџии этики исследования и применения технологий виртуальной реальности (TVR) и иммерсивного кинематографа». Первые круглье столы по ее обсуждению прочли в 2018 г. в Москве. Приведены их решения и план / дорожная карта профессионального сообщества по обсуждению декларации и связанных с ней проблем TVR до конияа 2018 года.

Ключевые слова: будущее; гуманитарная экспертиза; философия как экспертиза; антропологические риски; технологии виртуальной реальности; иммерсивный кинематограф; кодекс; этика; виртуалистика; добросовестность научных исследований 


\title{
Regulation of Virtual Reality Technologies: The First Russian Code of Ethical Behaviour
}

\author{
M. A. Pronin
}

Institute of Philosophy, Russian Academy of Sciences, O. N. Raev

\section{S. A. Gerasimov All-Russian State University of Cinematography}

The article presents the current situation with the ethical regulation of virtual, augmented and substitutional realities (TVR) in Russia. Within the framework of the "philosophy of expertise" (Boris G. Yudin's term), the authors briefly outline arguments that characterize the humanities dimension of TVR as a technology of conscience modification. They note that it is necessary to get these technologies under public, ethical and legal control.

The article contains a Russian translation of the first foreign "VERE Code of Conduct for the Ethical Use of VR in Research and by the General Public", published by M. Madary and T. Metzinger in 2016. It discusses the problems of the proactive behaviour of scientists and the readiness or unwillingness of the mass media to write not only about the opportunities but also about the threats and risks of TVR that are not fully known and thoroughly recognized.

The article describes the first steps of the Russian professional community engaged in the development, implementation and use of TVR, toward their regulation - to the development and discussion of the "Declaration of the Ethics of Research and Application of Virtual Reality Technologies (TVR) and Immersive Cinema". The first roundtables organized in order to discuss it took place in 2018 in Moscow. The article presents the decisions and roadmap of the professional community to discuss the declaration and related issues of TVR until the end of 2018.

Keywords: future; humanitarian expertise; philosophy as an expertise; anthropological risks; technologies of virtual reality; immersive cinema; code; ethics; virtualistics; good scientific practice

\section{ВВЕДЕНИЕ}

Настоящая статья - один из шагов на пути к созданию кодекса этического поведения в области регулирования технологии виртуальной (virtual reality - VR), дополненной (augmented reality - AR) и заместительной (substitutional reality - SR) реальностей - далее TVR, - которые относятся к технологиям «редактирования сознания» (Пронин, 2017). За рубежом первый подобный кодекс появился в 2016 г. (Madary, Metzinger, 2016), тогда как в России речь сегодня идет лишь о первом шаге - о декларации следовать в направлении его разработки и внедрения (Декларация этики ... , 2018).

Полагаем, что введение в научный оборот перевода с английского языка кодекса в версии зарубежных коллег - значимый шаг в продвижении идей гуманитарной безопасности TVR. Трудности перевода подобных доку- 
ментов, особенно на этапе становления терминов и понятий, дело не столь простое и однозначное; практика делового оборота в стране локализации не может не накладывать ограничения и привносить дополнительные трудности.

Подчеркнем, что, с одной стороны, сегодня, как и «вчера», в России проблемы безопасности технологий заслоняются жаждой развития и продвижения таковых: первый (13-15 апреля 2018 г.; см.: AVRA HACK AR/VR, 2018: Электронный ресурс)) и второй (14 ноября 2018 г.; см.: AVRA DAYS, 2018: Электронный ресурс) бизнес-форумы российской Ассоциации дополненной и виртуальной реальности (AVRA) оставляют все вопросы безопасности за бортом повестки. Технологии развиваются в «ситуации цейтнота» на свое этического осмысление; к российским реалиям развития TVR эти слова О. В. Поповой имеют самое прямое отношение (Попова, 2018: Электронный ресурс).

Однако «встречная» тенденция - тенденция гуманитарной настороженности, - в нашей стране понемногу набирает силу. В 2018 г. проведено два заседания круглого стола на тему «Виртуальная реальность: возможности и угрозы». Данные заседания задают перспективу «гуманитарного разминирования» возможностей TVR, которые, как и любые другие новые технологии «редактирования человека», несут с собой неизвестные и до конца не осознаваемые опасности.

Экспликация первых фактов — в какой-то степени даже «исторических событий», развития современной истории философии (этики) и науки в России в данной сфере - главная, но не единственная цель данной статьи. Редактирование текста, как известно, невозможно без понимания контекста; поэтому описание артефактов существенных для понимания логики истории формирования биоэтического дискурса TVR - вторая, не менее важная, цель данной работы.

\section{ФИЛОСОФИЯ КАК ЭКСПЕРТИЗА И ТЕХНОЛОГИИ РЕДАКТИРОВАНИЯ СОЗНАНИЯ}

Не будем повторять аргументов из наших предыдущих публикаций (Пронин, 2018) в пользу применения логики «философии как экспертизы» (термин Б. Г. Юдина (Юдин, 2017)) к TVR, развернутую дискуссию о таковой Б. Г. Юдина и М. А. Пронина в цикле философских бесед «Реплики» Института философии РАН можно посмотреть в Интернете (Философия как экспертиза, 2016: Электронный ресурс) (по ее итогам подготовлена публикация (Пронин, Синеокая, Юдин, 2017)), так как часть российского профессионального сообщества специалистов, занимающихся применением TVR в разных областях, в частности в кинематографе, с пониманием отнеслась к оценке или трактовке всего спектра подобных технологий как технологий редактирования сознания. Понимание, что технологии, заведомо обманывающие 
сознание человека, должны быть поставлены под должный контроль со стороны профессионалов, общества и государства — нашло поддержку ученых и специалистов из разных институтов и организаций, которая выразилась в том числе в их активном и заинтересованном участии в работе двух круглых столов «Виртуальная реальность: возможности и угрозы». Однако мы вынуждены констатировать, что российский контекст применения массовых приложений TVR пока соответствует начальной стадии - стадии неквалифицированного интереса к отрицательным последствиям их использования.

Конечно же, теоретическая повестка исследований виртуального человека, как его понимают последователи школы Н. А. Носова (1952-2002; Носов, 1997), также задает контекст для разработки всей линии гуманитарного / общественного, этического и юридического регламентирования исследований, разработок и практического применения продуктов TVR на их основе. Без решения целого ряда теоретических вопросов гуманитарная и биоэтическая экспертиза данных технологий будет затруднена.

В качестве корневых теоретических проблем можно назвать следующие.

Как задавать полионтологичную иерархию в пространстве, недоступном внутреннему наблюдению: интроспекций, рефлексии и т. п.? Имеется в виду пространство внутреннего человека - именно его виртуалистика понимает виртуальным, - а не антропологию экранного аватара.

Как задавать онтологии синтетических, порождаемых, временных, автономных, актуальных онтологий? Как определять онтологический статус взаимозависимых реальностей или объектов, находящихся в интерактивных отношениях «взаимопорождения - взаимокоррекции»? Как строить динамические онтологические схемы с переменным центром координат? В логике принятия решений - что брать в качестве приоритета, начала координат: рациональное, эмоциональное, опыт / телесность и пр.? Пространство TVR и является таковым!

Как выстраивать онтологию в схеме рациональности теоретического знания В. С. Степина (Степин, 2000)? Чем различаются «человеки» на месте объекта, инструмента и субъекта исследований, тем более, когда объект, инструмент и субъект - один и тот же человек?

Как задавать онтологии неразличения в феноменах ошибки? Человек описался, оговорился, ослышался, обознался, «запутался» в конце концов! Данные остенсивные примеры, из которых вырастала виртуалистика Н. А. Носова (Носов, 1990), вскрывают типичную онтологию феноменов «редактирования сознания». В общем виде это можно сформулировать так: как разбираться с порождением неадекватных эпистемологий у исследователей, когда неадекватность ими не различается годами, десятилетиями, столетиями до свершения парадигмальной революции? 
Не будем дальше перечислять. Присутствие теоретического проблемного поля в настоящей работе задает значимый контекст, детерминирующий реалии продвижения профессионалов и широкой общественности в сторону должного регулирования TVR.

Более того, на наш взгляд, гуманитарная и биоэтическая экспертиза, вопервых, и философия как экспертиза, во-вторых, именно на предмете нормирования TVR как технологий редактирования сознания смогут приобрести новые социальные, производственные (имеется в виду наука как производство) и культурные черты.

\section{ПЕРВЫЙ КОДЕКС \\ ЭТИЧЕСКОГО ПОВЕДЕНИЯ В СФЕРЕ TVR}

Следует понимать, что «редактирование сознания» - это не метафора, но механизм работы TVR, который изначально направлен на обман сознания - на достижение феномена неразличения человеком искусственной (порожденной технологиями) и его жизненной реальностей. Уже сегодня TVR и их приложения способны обеспечить неразличение человеком не только своих и чужих мыслей, но и своей и чужой воли, своего и чужого тела, своей и чужой личности, своего внутреннего человека и человека внешнего - навязанного. Все остальные технологии «оцифровки человека» - лишь следствия успешности либо неуспешности решения данной сверхзадачи.

Под термином «виртуальный», как пишет А. Е. Войскунский, в современной науке и философии мейнстрима понимается все, что происходит в Интернете, киберпространстве и пр.; в результате слово «виртуальный» сегодня ничего не означает и ничего не объясняет (Войскунский, 2016). Таким образом, борьба за смысл слова «виртуальный» в философии и «науке мейнстрима» - в преобладающих все последние годы разработках и исследованиях, — закончилась «ничем».

Подобные вещи происходят, потому что природная виртуальность человека находится в «коллективном когнитивном неосознаваемом» (термин М. А. Пронина; не путать с коллективным когнитивным бессознательным А. В. Смирнова) философии и науки мейнстрима как у нас в России, так и за рубежом. Иными совами, TVR не работали бы, если бы «не работала» природная виртуальность человека (Пронин, 2016b).

Это глобальная парадигмальная проблема - без ее восприятия, исследования и разработки решений адекватная опережающая трансформация / развитие институционального регулирования в области цифровых технологий затруднительна, если вообще возможна.

В этой связи появление кодексов этического поведения в области научных исследований, регламентирующих их добросовестность (good scientific practice) и безопасность потребителей TVR, становятся насущной необходимостью нашего времени. 
B результате обсуждений в рамках Virtual Embodiment and Robotic ReEmbodiment (VERE) - 5-летняя исследовательская программа, субсидируемая Европейской комиссией, - был разработан «VERE-кодекс этического поведения. Рекомендации для добросовестных научных исследований и потребителей VR-технологий», опубликованный М. Мадари и T. Метцингером (Madary, Metzinger, 2016); см. одноименную таблицу.

Таблица 1

\section{VERE ${ }^{1}$-кодекс этического поведения.}

\section{Рекомендации для добросовестных научных исследований (good scientific practice) и потребителей $V R^{2}$-технологий ${ }^{3}$ VERE Code of Conduct for the Ethical Use of VR in Research and by the General Public ${ }^{4}$}

\section{Этические рекомендации для исследований VR \\ 1. Не навреди}

а. Эксперименты с использованием виртуальной реальности (VR) не должны проводиться, если можно прогнозировать, что при этом субъекту (subject) будут причинены недобровольные (involuntary) страдания или значительный, или долговременный (lasting) ущерб.

b. Рациональная, научно обоснованная идентификация и минимизация рисков (в том числе и тех, которые могут относиться к отдаленному будущему) должна быть частью самого исследования.

2. Информированное согласие

\footnotetext{
${ }^{1}$ Virtual Embodiment and Robotic Re-Embodiment (VERE) - 5-летняя исследовательская программа, субсидируемая Европейской комиссией. Проект, в котором участвуют авторы, а также текущая публикация финансируются в рамках 7-й рамочной программы ЕС «Будущие и появляющиеся технологии» (Framework Program "Future and Emerging Technologies”; грант 257695). Проект VERE направлен на «растворение границы» между человеческим телом и его суррогатными представлениями в виртуальной реальности и физической реальности, когда у людей создается иллюзия того, что их суррогатное представление является их собственным телом. См. подробнее: http://www.vereproject.eu. Авторы благодарят членов консорциума VERE за обсуждение многих вопросов данной статьи во время семинаров "VERE Ethics Workshops" в феврале 2013 года и в сентябре 2015 года.

${ }^{2}$ VR - virtual reality - виртуальная реальность (BP); AR — augmented reality — дополненная реальность (AR); SR — substitutional reality - замещающая реальность (SR).

3 Перевод М. А. Пронина: http://iph.ras.ru/pronin.htm; www.виртулистика.py. Выражаем признательность Р. А. Искандаряну за предоставленные материалы и компании Emporium Linguae за поддержку в переводе.

${ }^{4}$ Реальная виртуальность: Кодекс этического поведения. Рекомендации для добросовестных научных исследований (good scientific practice) и потребителей ВР-технологий. См.: Madary, Metzinger, 2016.
} 
а. Информированное согласие для экспериментов c VR должно содержать открытое (an explicit) заявление о том, что VR с эффектом погружения (immersive) может оказывать долговременное воздействие на поведение субъектов (subjects) экспериментов и риски их могут быть в настоящее время неизвестны.

b. Экспериментальные исследования VR не должны проводиться на субъектах (subjects), неспособных (incapable) к информированному согласию.

3. Прозрачность (transparency) и медиаэтика

а. В ходе экспериментов по разработке новых клинических приложений исследователям следует проявлять осторожность и не создавать у пациентов ложных надежд (false hopes), неоднократно напоминая им о сугубо экспериментальном характере исследования.

b. Исследователи VR, разрабатывающие новые клинических приложения, должны работать в тесном сотрудничестве с врачами, которые в большей степени подходят для того, чтобы выносить обоснованные заключения о допуске конкретных пациентов к новым испытаниям.

с. Ученые и средства массовой информации должны ясно и честно информировать общественность о научном прогрессе, причем не только в сфере использования VR для оказания медицинской помощи.

d. В общении со средствами массовой информации ученым следует культивировать в себе проактивный подход, особенно когда им первым в процессе собственной работы становится известно о новых типах рисков. Обращение к общественности, в необходимых случаях, должно быть инициировано самими учеными, чтобы взять происходящее под контроль и действовать на опережение будущей ситуации, а не просто реагировать на нее.

4. Двойное назначение

а. Возможное использование $\mathrm{VR}, \mathrm{AR}$ и $\mathrm{SR}$ в военных целях должно находиться под тщательным контролем директивных органов (policy makers) и финансирующих организаций.

b. Пытки в виртуальной среде остаются пытками. Тот факт, что чье-либо страдание происходит при погружении в виртуальную среду, не смягчает страдания как такового. с. Директивные органы (policy makers) должны направить усилия на заключение международных договоренностей между странами для внесения VR, AR и SR в процесс согласования (harmonize) перечней контролируемых технологий двойного назначения.

\section{5. Интернет-исследования}

а. Научное сообщество должно сделать шаги, направленные на избежание злоупотреблений информированным согласием с данной технологией, особенно в интересах сохранения общественного доверия.

b. Возможность переключаться между VR, AR и SR может создавать ситуации в кото- 
рых пользователи не способны сохранять понимание того, когда их информированное согласие делиться информацией действует. Пользователям в VR необходимо постоянно напоминать о том, что они дали информированное согласие.

6. Ограничения для Кодекса поведения

а. Ученые обязаны (must) понимать, что следовать этическому кодексу 一 это не то же самое, что быть (курсив в первоисточнике. - М. П., О. Р.) этичным. Этический кодекс конкретной предметной области, как бы он ни был последовательным, развитым и до мельчайших подробностей проработанным в его будущих версиях, не может функционировать в качестве замены этическому мышлению (ethical reasoning) как таковому.

b. Подобное мышление должно (must) быть чувствительно к контексту и деталям peaлизации особенностей конкретных экспериментальных парадигм, к деталям, которые невозможно ухватить общим кодексом поведения.

\section{Рекомендации по использованию VR широкой общественностью}

1. Долговременное погружение (long-term immersion)

а. Необходимы продольные исследования (longitudinal studies) с изучением будущих психологических последствий долговременного погружения.

b. Пользователи должны осознавать, что подобные исследования серьезно сужены этическими ограничениями; в них не будут участвовать наиболее уязвимые категории пользователей (такие как дети или лица со скрытыми психическими заболеваниями). Некоторые из таких уязвимостей могут быть неизвестны науке и неизвестны самим пользователям.

2. Нарастает виртуализации социальных взаимодействий - мы призываем к целенаправленному изучению (focused research), к большим продольным исследованиям (large longitudinal studies) следующих вопросов:

а. Что именно, если вообще, теряется при социальных взаимодействиях, опосредованных (mediated) передовыми формами телеприсутствия в VR?

b. Если подобные потери не были замечены, то какие негативные эффекты для самообраза человека (the human self-model) можно ожидать?

\section{3. Контент повышенного риска}

а. По сравнению с просмотром традиционных фильмов, содержащих сцены насилия или порнографию, по мере развития технологии VR воздействие режима полного погружения (full immersion settings) и связанный с ним риск получения пользователями психологической травмы будет неуклонно нарастать. Пользователи должны быть осведомлены о такой возможности.

b. Технология VR содержит в себе потенциал для создания устойчивых (robust) социальных галлюцинаций, для прямого манипулирования чувством агента, для модулиро- 
вания черт личности (personality traits) посредством идентификации с виртуальными персонажами или для причинного взаимодействия (to causally interact) с более глубокими уровнями самосознания (UI-manipulation ${ }^{5}$; манипуляция единицами идентификации пользователя - “unit of identification”). Пользователи должны быть осведомлены о такой возможности.

с. Право собственности на аватар станет важным вопросом для агентств-регуляторов. Имеются веские причины для введения ограничений на допустимый порядок использования аватаров, включая защиту интересов и частной жизни лиц, которые в высокой степени отождествляют себя с собственным аватаром в социальных сетях. С другой стороны, такие ограничения могут оказаться практически неосуществимыми и неоправданно ограничивать личную свободу творчества. Регуляторы обязаны (must) установить (strike) разумный баланс между данными опасностями.

4. Частная жизнь (privacy)

а. Пользователи должны быть осведомлены о том, что есть доказательства того, что тактики рекламы, использующей технологию воплощения, такую как VR, могут оказывать мощное неосознаваемое воздействие на поведение. Например, сочетание стратегий “Big Nudging” (сбор больших объемов данных в целях манипуляции (nudging) широкой общественностью) с технологией VR может иметь долговременные последствия (long-lasting effects), которые могут поражать (affect) глубинные психические механизмы.

b. Защита данных: пользователи должны быть осведомлены о новых рисках слежки за ними (involving surveillance), таких как считывание их двигательных намерений (motor intentions) или «кинематических “отпечатков пальцев“» (kinematic fingerprint) в процессе использования ими аватара.

Все пункты данного кодекса «подтверждены» обзором касающейся темы киберпространства научной литературы как последних лет, так и 80-х гг. прошлого века и даже более ранней (вплоть до 1950-х гг.), имеющей отношение к социальным и психологическим особенностям поведения человека. Последняя - выступает «контрольной группой» для исследований с использованием TVR.

Полагаем, что пересказывать и комментировать Кодекс в данной статье не имеет смысла; заинтересованные смогут познакомиться с полной аргументацией, обратившись к публикации М. Мадари и Т. Метцингера (Madary, Metzinger, 2016). Но все же остановимся на двух моментах - во-первых, на

\footnotetext{
${ }^{5}$ UI (phenomenal “unit of identification”) - единица (само)идентификации человека. Специфический термин из области исследований сознания. Не следует путать с "UI - user interface" - c интерфейсом пользователя. UI - это специфическое наполнение «индивидуальности» человека в соответствующих экспериментах с использованием BP (Metzinger, 2013ab).
} 
единственном слове, выделенном в данном Кодексе курсивом: это пункт 6а — «Ученые обязаны (must) понимать, что следовать этическому кодексу — это не то же самое, что быть этичным».

Затем Кодекс раскрывает некоторые аспекты данного противоречия: «Этический кодекс конкретной предметной области, каким бы последовательным, развитым и до мельчайших подробностей проработанным в его будущих версиях он не был, не может функционировать в качестве замены этическому мышлению (ethical reasoning) как таковому». И далее: «6b. Подобное мышление должно (must) быть чувствительно к контексту и деталям реализации особенностей конкретных экспериментальных парадигм, к деталям, которые невозможно ухватить общим кодексом поведения». Вполне определенно, что в данном контексте должно говорить об апорийности этического мышления и поведения в области регламентации TVR! Tем самым, как, впрочем, в гуманитарной экспертизе любых новых технологий, закладывается если не когнитивный диссонанс, то вполне определенное когнитивное напряжение - и издержки, в том числе экономические и / или организационные! Поэтому все это влечет за собой вполне очевидные дополнительные обязательства и расходы.

Более того, вновь обнаруженные или даже заподозренные риски и их последствия требуют прозрачности (transparency) и специфической медиаэтики (п. 3, подпункт d) - проактивного взаимодействия ученых и представителей средств массовой информации (СМИ). Это второй момент, который мы хотели бы прокомментировать.

Готовность современных СМИ писать о непонятном и далеко не известном - вызывает некоторые, мягко говоря, сомнения. Этическое мышление и поведение журналистов в сфере научно-популярного пространства была, есть и будет большой проблемой для современной эмоциональной журналистики. Содержательная журналистика находится на периферии «журналистского» мейнстрима по целому ряду вполне очевидных обстоятельств (Пронин, 2016а). Поэтому, к сожалению, бремя общения с обществом ученому-исследователю и разработчику переложить чаще всего не на кого.

Все вышеприведенные аргументы и обстоятельства, как, впрочем, и оставшиеся вне обозрения, заставляют определенную часть российского сообщества «TVR-специалистов» начать проактивное движение от самооценки ситуации «как есть» (“it is” — на языке бизнес реинжениринга) в сторону самоорганизации, самомотивации и самонацеливания на целевое состояние “tо be” - как должно быть: к осмыслению не только и не столько возможностей TVR, сколько опасностей, противопоказаний и ограничений. Пока, как уже было сформулировано выше, ситуация «как есть» характеризуется стадией проявления начального - неквалифицированного — интереса к отрицательным последствиям их использования. 
РОССИЙСКАЯ ТVR-ИНДУСТРИЯ: ПЕРВЫЕ ШАГИ

НА ПУТИ К ЭТИЧЕСКОМУ САМОРЕГУЛИРОВАНИЮ

Цифровая экономика, о которой сегодня не говорит лишь ленивый, с неизбежностью проявит достаточно тривиальный, но не очевидный для большинства ее апологетов тезис: мировоззрение и этика становятся факторами производства и потребления в XXI в. Одним из его следствий станет «инновационный предикат этики» или «предикат этики в инновациях» в том смысле, что этическая зрелость художника / творца должна опережать уровень его производственной / ремесленной состоятельности. Развитые социальные управленческие технологии, реализующие «этический предикат развития» на уровне обычаев делового оборота, сегодня отсутствуют не только в России, но и на Западе. Более того, это та самая «гуманитарная оболочка инноваций», которая отсутствует в современной России; но тему сопоставления отличий оставим для другого случая.

Внутриотраслевой контекст применения TVR и осознания вышерассмотренных их особенностей, значимых для логики нашего рассуждения, задает еще один элемент гуманитарной оболочки. Де-факто он состоит в следующем: с 2009 года по 2018 год сначала Московское конструкторское бюро киноаппаратуры (МКБК) совместно с Московским киновидеоинститутом (МКВИ), а в последние годы Всероссийский государственный институт кинематографии имени С. А. Герасимова (ВГИК) провели 10 ежегодных научно-практических конференций «Запись и воспроизведение объемных изображений в кинематографе и других областях». Выпущено 9 сборников докладов и материалов конференции (Запись и воспроизведение ..., 2009, 2010, 2012, 2013ab, 2014, 2015, 2016, 2017), сейчас готовится десятый. С 2014 года по 2018 год было проведено пять ежегодных научно-практических конференций «Инновационные технологии в кинематографе и образовании». Выпущено 4 сборника (Инновационные технологии ... , 2014, 2015, 2016, 2017). Сейчас идет издательская подготовка пятого сборника.

Первоначально конференции были организованы для объединения ученых и специалистов-практиков, занимающихся технологиями создания, преобразования и демонстрации изображений, для организации площадки, содействующей обмену опытом и информацией, конструктивному диалогу специалистов из различных областей и созданию условий содействия для выработки коллективных решений, поддержанию отечественного научного уровня в этих направлениях соответствующим мировому. Технические аспекты всегда рассматривались во взаимосвязи с качеством восприятия изображений и их влияния на самочувствие, комфорт и здоровье человека. Но пока еще нет ни значимого эмпирического базиса, ни общепризнанных и / или общепринятых теоретических разработок для оценки безопасности и нормирования данных технологий (Пронин, 2017). 
В настоящее время научное и практическое сообщество, объединенное указанными мероприятиями, пришло к необходимости расширения тематики анализа и исследований данного направления в сторону юридического, этического регулирования и гуманитарного сопровождения внедряемых TVR.

Так, в результате решения, принятого участниками $\mathrm{X}$ научнопрактической конференции «Запись и воспроизведение объемных изображений в кинематографе и других областях», проходившей 16-18 апреля 2018 г. в Москве во ВГИКе, был организован и проведен 30 мая 2018 г. первый круглый стол «Виртуальная реальность: возможности и угрозы», а 5 октября 2018 г. уже второй круглый стол с тем же названием. Организаторами второго круглого стола «Виртуальная реальность: возможности и угрозы» выступили Международный институт новых образовательных технологий Российского государственного гуманитарного университета (РГГУ), Гильдия кинотехников Союза кинематографистов Российской Федерации и Институт философии Российской академии наук.

Целью его работы стало обсуждение проекта «Декларации этики исследования и применения технологий виртуальной реальности (TVR) и иммерсивного кинематографа» (Декларации этики ... , 2018), разрабатываемого во исполнение решений X научно-практической конференции «Запись и воспроизведение объемных изображений в кинематографе и других областях».

Основной доклад был подготовлен Рубеном Александровичем Искандаряном (Российский национальный исследовательский медицинский университет им. Н. И. Пирогова).

В работе второго круглого стола приняли участие 31 ученый, специалист, аспирант и студент из 25 организаций Москвы и Московской области; каждый из участников круглого стола выступил или высказался.

Шаг в сторону декларации, но не Кодекса, вынужденный, основанный на понимание реалий и обстоятельств в отечественной отрасли TVR. Профессиональное сообщество посчитало необходимым начать широкое обсуждение с целью донесения до коллег и стейкхолдеров осознания всего проблемного поля TVR и побуждения их к согласию с необходимостью должной гуманитарной настороженности и выражению соответствующих намерений через присоединение к «Декларация этики технологий виртуальной реальности (TVR) и иммерсивного кинематографа».

\section{ЗАКЛЮЧЕНИЕ}

К создаваемым и активно внедряемым новым TVR должна быть проявлена общественная и государственная гуманитарная настороженность. Пониманию возможных проблем от их внедрения содействуют необходимые исследования, популяризация их результатов через СМИ и, самое главное, инициирование критического отношения ученых и специалистов, занимаю- 
щихся этими технологиями, к возможным последствиям от их применения. Этому могут содействовать следующие мероприятия.

1. Разработка, широкое обсуждение и принятие «Декларации этики исследования и применения технологий виртуальной реальности (TVR) и иммерсивного кинематографа».

2. Регулярное проведение встреч научной общественности для всестороннего обсуждения достижений и проблем в сфере гуманитарной безопасности TVR. K ним относится секция, посвященная технике и технологиям виртуальной и дополненной реальности в рамках $\mathrm{V}$ научно-практической конференции «Инновационные технологии в кинематографе и образовании» (12-13 ноября 2018 г., РГГУ).

3. Рекомендуется в рамках мероприятий Девятого 3D-стерео кинофестиваля, запланированного на 13-14 декабря 2018 г., провести круглый стол по этическим и медико-психологическим проблемам сценариев, режиссуры, съемки и показа фильмов, предназначенных для демонстрации с применением очков и шлемов виртуальной реальности. Данные обсуждения станут частью VIII научно-практических чтений памяти Н. А. Носова на тему «Философия как экспертиза: этика как фактор производства социального благополучия человека в мире».

\section{СПИСОК ЛИТЕРАТУРЫ}

Войскунский, А. Е. (2016) Поведение в киберпространстве: психологические принципы // Человек. № 1. С. 36-49.

Декларация этики технологий виртуальной реальности (TVR) и иммерсивного кинематографа (2018) [Электронный ресурс] // ВИРТУАЛИСТИKA.RU. 5 октября. URL: http://www.virtualistika.ru/trz_meropr.html [apхивировано в WaybackMachine] (дата обращения: 10.10.2018).

Запись и воспроизведение объемных изображений в кинематографе и других областях (2009) : научно-техническая конференция, Москва, 23-24 апреля 2009 г. : материалы и доклады / под общ. ред. О. Н. Раева. М. : МКБК. $216 \mathrm{c}$.

Запись и воспроизведение объемных изображений в кинематографе и других областях (2010) : Вторая научно-техническая конференция, Москва, 22-23 апреля 2010 г. : материалы и доклады / под общ. ред. О. Н. Раева. М. : МКБК. 223 с.

Запись и воспроизведение объемных изображений в кинематографе и других областях (2012) : III Международная научно-техническая конференция, Москва, 21-22 апреля 2011 г. : материалы и доклады / под общ. ред. О. Н. Раева. М. : МКБК. 224 с.

Запись и воспроизведение объемных изображений в кинематографе и других областях (2013a) : IV Международная научно-техническая конференция, Москва, 26-27 апреля 2012 г. : материалы и доклады / под общ. ред. О. Н. Раева. М. : МКБК. 288 с. 
Запись и воспроизведение объемных изображений в кинематографе и других областях (2013b) : V Международная научно-техническая конференция, Москва, 18-19 апреля 2013 г. : материалы и доклады / под общ. ред. О. Н. Раева. М. : МКБК. 303 с.

Запись и воспроизведение объемных изображений в кинематографе и других областях (2014) : VI Международная научно-практическая конференция, Москва, 17-18 апреля 2014 г. : материалы и доклады / под общ. ред. О. Н. Раева. М. : ВГИК. 307 с.

Запись и воспроизведение объемных изображений в кинематографе и других областях (2015) : VII Международная научно-практическая конференция, Москва, 23-25 апреля 2015 г. : материалы и доклады / под общ. ред. О. Н. Раева. М. : ВГИК. 303 с.

Запись и воспроизведение объемных изображений в кинематографе и других областях (2016) : VIII Международная научно-практическая конференция, Москва, 25-26 апреля 2016 г. : материалы и доклады / под общ. ред. О. Н. Раева. М. : ВГИК. 323 с.

Запись и воспроизведение объемных изображений в кинематографе и других областях (2017) : IX Международная научно-практическая конференция, Москва, 17-18 апреля 2017 г. : материалы и доклады / под общ. ред. О. Н. Раева. М. : ВГИК. 312 с.

Инновационные технологии в кинематографе и образовании (2014) : Научно-практическая конференция, Москва, 29-31 октября 2014 г. : материалы и доклады / под общ. ред. О. Н. Раева. М. : ВГИК. 223 с.

Инновационные технологии в кинематографе и образовании (2015) : II Международная научно-практическая конференция, Москва, 21-25 сентября 2015 г. : материалы и доклады / под общ. ред. О. Н. Раева. М. : ВГИК. 284 c.

Инновационные технологии в кинематографе и образовании (2016) : III Международная научно-практическая конференция, Москва, 28-30 сентября 2016 г. : материалы и доклады / под общ. ред. О. Н. Раева. М. : ВГИК. 299 c.

Инновационные технологии в кинематографе и образовании (2017) : IV Международная научно-практическая конференция, Москва, 26-29 сентября 2017 г. : Материалы материалы и доклады / под общ. ред. О. Н. Раева. М. : ВГИК. 267 c.

Носов, Н. А. (1990) Ошибки пилота: психологические причины. М. : Транспорт. 64 с.

Носов, Н. А. (1997) Виртуальный человек: очерки по виртуальной психологии детства. М. : Магистр. 192 с.

Попова, О. В. (2018) Этика работает в режиме цейтнота [Электронный pecypc] // Огонёк. № 9. 12 марта. C. 29. URL: https://www.kommersant.ru/doc/ 3568912 [архивировано в WaybackMachine] (дата обращения: 10.10.2018).

Пронин, М. А. (2016а) «Не судьба» научно-популярной журналистики в России [Электронный ресурс] // Экология и жизнь (электронная версия 
журнала). URL: http://ecolife.ru/zhurnal/articles/43490/ [архивировано в WaybackMachine] (дата обращения: 10.10.2018).

Пронин, М. А. (2016b) Вызовы мировоззрению разработчиков технологий виртуальной реальности (TVR): философские, этические, юридические и другие следствия // Философия образования. № 6 (69). С. 46-69. DOI: 10.15372/PHE20160605

Пронин, М. А. (2017) Философия как экспертиза: к пониманию природы противопоказаний к применению технологий виртуальной / дополненной реальности (TVR/AR) // Инновационные технологии в кинематографе и образовании : IV Международная научно-практическая конференция, Москва, 2629 сентября 2017 г. : материалы и доклады / под общ. ред. О. Н. Раева. М. : ВГИК. 267 с. С. $117-129$.

Пронин, М. А. (2018) Технологии виртуальной реальности (TVR) и парадигмальный Рубикон психологии // Актуальные проблемы психологии труда, инженерной психологии и эргономики / под ред. А. А. Обознова, А. Л. Журавлева. Вып. 8. М. : Ин-т психологии РАН. 568 с. С. 115-134.

Пронин, М. А., Синеокая, Ю. В., Юдин, Б. Г. (2017) Философия как экспертиза // Философский журнал. Т. 10. № 2. С. 79-96. DOI: 10.21146/20720726-2017-10-2-79-96

Степин, В. С. (2000) Теоретическое знание. М. : Прогресс-Традиция. $744 \mathrm{c}$.

Философия как экспертиза (2016) : видеозапись дискуссии / Б. Г. Юдин, М. А. Пронин, Ю. В. Синеокая / Цикл философских бесед «Реплики» Института философии РАН [Электронный ресурс] // YouTube. 9 июня. URL: https://www.youtube.com/watch?v=BAYwaHT_m7g (дата обращения: 10.10.2018).

Юдин, Б. Г. (2017) О понятии философской экспертизы // Ценностные основания научного познания / отв. ред. Г. Л. Белкина; ред.-сост. М. И. Фролова. М. : URSS ; ЛЕНАНД. 310 с. С. 45-56.

AVRA HACK AR/VR (2018) [Электронный pecypc]. URL: https:// avrahackathon.ru/ [архивировано в WaybackMachine] (дата обращения: 10.10. 2018).

AVRA DAYS (2018) [Электронный ресурс] // Ассоциация дополненной и виртуальной реальности. URL: https://avradays.com/\#about [архивировано в WaybackMachine] (дата обращения: 10.10.2018).

Madary, M., Metzinger, T. K. (2016) Recommendations for good scientific practice and the consumers of VR-technology // Frontiers in Robotics and AI. Vol. 3. Article 3. DOI: $10.3389 /$ frobt.2016.00003

Metzinger, T. (2013a) The myth of cognitive agency: subpersonal thinking as a cyclically recurring loss of mental autonomy // Frontiers in Psychology. Vol. 4. Article 931. DOI: 10.3389/ fpsyg.2013.00931

Metzinger, T. (2013b) Why are dreams interesting for philosophers? The example of minimal phenomenal selfhood, plus an agenda for future research // Frontiers in Psychology. Vol. 4. Article 746. DOI: 10.3389/fpsyg.2013.00746 
Дата поступления: 10.10.2018 2.

Пронин Михаил Анатольевич — кандидат медицинских наук, старший научный сотрудник сектора гуманитарных экспертиз и биоэтики, руководитель исследовательской группы «Виртуалистика» Института философии Российской академии наук. Адрес: 109240, Россия, г. Москва, ул. Гончарная, д. 12, стр. 1. Тел.: +7 (495) 697-91-09. Эл. адрес: pronin@iph.ras.ru

Pronin Mikhail Anatolievich, Candidate of Medicine, Senior Research Fellow, Department of Humanitarian Expertise and Bioethics, Head of Research Group "Virtualistics", Institute of Philosophy, Russian Academy of Sciences. Postal address: Bldg. 1, 12, Goncharnaya St., 109240 Moscow, Russian Federation. Tel.: +7 (495) 697-91-09. E-mail: pronin@iph.ras.ru

SPIN-код в РИНЦ: 3114-0112. ORCID: 0000-0003-0594-6500. SCOPUS: 6701662940. Researcher ID: V-1730-2018.

Раев Олег Николаевич - кандидат технических наук, доцент, заведующий кафедрой аудиовизуальных технологий и технических средств Всероссийского государственного института кинематографии имени С. А. Герасимова. Адрес: 129226, Россия, г. Москва, ул. Вильгельма Пика, д. 3. Тел.: +7 (499) 760-29-95. Эл. адрес: ncenter@list.ru

Raev Oleg Nikolaevich, Candidate of Engineering, Associate Professor, Head, Department of Audiovisual Technologies and Technical Means, S. A. Gerasimov All-Russian State University of Cinematography (VGIK). Postal address: 3, Vilgelma Pika St., 129226 Moscow, Russian Federation. Tel.: +7 (499) 760-29-95. Эл. адрес: ncenter@list.ru

SPIN-код в РИНЦ: 8199-6814

Для циитирования:

Пронин М. А., Раев О. Н. Регулирование технологий виртуальной реальности: к первому российскому кодексу этического поведения [Электронный ресурс] // Горизонты гуманитарного знания. 2018. № 5. С. 109-124. URL: http://journals.mosgu.ru/ggz/article/view/876 (дата обращения: дд.мм.гггг). DOI: 10.17805/ggz.2018.5.9 